\title{
CREATINE METABOLISM AND THE GONADS
}

\author{
BY \\ PAUL KAHN, M.D., L.R.C.S. \& P., \\ AND \\ NATHANIEL SMITH.
}

(From the Princess Elizabeth of York Hospital for Children, London.)

It has long been recognized that endogenous creatine is a normal constituent of the urine of the infant and the child, whereas in the adult, unless in the female during pregnancy and the first few days of the puerperium, no creatine is excreted in the urine. Although it has been apparent that this change in metabolism occurs about the time of puberty, and it has been surmised that it may be associated with the activity of the gonads, there is not extant any sufficiently long series of observations demonstrating the fact conclusively. It is for this reason-to determine the exact age at which this change takes place and to correlate it if possible with sexual development-that the following investigation was undertaken. In the series of cases investigated, children of all ages and of both sexes from infancy till after puberty are included. Unfortunately, however, owing to the fact that it is difficult to accommodate boys of the older ages in a children's hospital the numbers of males about puberty are relatively small, but this would seem in no way to detract from the conclusiveness of the results.

\section{Methods.}

The children studied were confined to bed in hospital so that the diet and the urinary output could be controlled. They were given the following standard diet during the whole course of the investigation:-

Bread, butter, marmalade, eggs, vegetables and fruit with milk which was restricted to $10 \mathrm{oz}$. per day for all the children except the infants. (No meat, fish, meat extracts, fowl or cheese allowed.)

It must, of course, be appreciated that milk contains a small amount of creatine (9 to $10 \mathrm{mgm}$. per cent.) but this is probably not more than the average individual can metabolize. After two preliminary days on this diet the total urine was collected and three successive twenty-four hours' specimens, i.e., those of the third, fourth and fifth days, were examined for creatine and creatinine according to Folin's method. The daily averages are recorded in the accompanying tables. 
TABLE 1.

AVERAGE CREATINE EXCRETION IN TWENTY-FOUR HOURS. BOYS.

\begin{tabular}{|c|c|c|c|c|c|c|c|}
\hline $\begin{array}{l}\text { CASE } \\
\text { No. }\end{array}$ & \multicolumn{3}{|c|}{ AGE } & $\begin{array}{c}\text { WEIGHT } \\
\text { KGM. }\end{array}$ & $\begin{array}{c}\text { CREATININe } \\
\text { EXCRETION } \\
\text { MGM. }\end{array}$ & $\begin{array}{l}\text { CREatiNe. } \\
\text { EXCRETION } \\
\text { MGM. }\end{array}$ & Remarks \\
\hline 1 & \multicolumn{3}{|c|}{7 mth. } & 5 & 80 & 95 & \\
\hline 2 & 7 & \multicolumn{2}{|c|}{, } & $5 \cdot 5$ & 84 & 119 & \\
\hline 3 & 8 & \multicolumn{2}{|l|}{, } & $6 \cdot 1$ & 78 & 113 & \\
\hline 4 & $1 \mathrm{yr}$ & & & 9 & 97 & 105 & \\
\hline 5 & 1, & \multicolumn{2}{|c|}{$6 \mathrm{mth}$. } & 10.9 & 144 & 115 & \\
\hline 6 & 1, & 11 &, & $9 \cdot 1$ & 152 & 120 & \\
\hline 7 & 4, & 8 & , & $30 \cdot 4$ & 365 & 153 & \\
\hline 8 & 5, & 1 & , & $17 \cdot 2$ & 271 & $\mathbf{1 7 3}$ & \\
\hline 9 & 5, & 1 & , & $17 \cdot 1$ & 254 & 127 & \\
\hline 10 & 7, & 9 & , & 25 & 459 & 143 & \\
\hline 11 & 8, & 5 & , & $34 \cdot 5$ & bั53 & 127 & \\
\hline 12 & 12, & & & $54 \cdot 5$ & 839 & none & \\
\hline 13 & 12, & & mth. & $63 \cdot 3$ & 752 & 145 & \\
\hline 14 & 12, & 8 & , & $41 \cdot 4$ & 764 & none & \\
\hline 15 & 12, & 9 & , & $35 \cdot 7$ & 655 & none & \\
\hline 16 & 12, & 10 &, & 77 & 1253 & none & \\
\hline 17 & 13, & & & $37 \cdot 7$ & 735 & none & \\
\hline 18 & 13, & & mth. & $49 \cdot 1$ & 870 & none & very well developed \\
\hline 19 & 13, & 5 & , & $50 \cdot 4$ & 755 & 90 & \\
\hline 20 & 13, & 5 & , & 75 & 940 & 160 & \\
\hline 21. & 13, & 6 & , & $\mathbf{3 4 \cdot 5}$ & 422 & none & \\
\hline & & & & & $\begin{array}{l}\text { ABLE } 2 . \\
\text { GIRLS. }\end{array}$ & & \\
\hline 1 & $1 \mathrm{yr}$. & .11 & mth. & $9 \cdot 1$ & 179 & 100 & \\
\hline 2 & 3, & 7 &, & $11 \cdot 1$ & 147 & 92 & \\
\hline 3 & 5, & 3 & , & $27 \cdot 3$ & 436 & 96 & \\
\hline 4 & 6, & 6 & , & $15 \cdot 5$ & 237 & 95 & \\
\hline $\mathbf{5}$ & 7, & & & $22 \cdot 6$ & 438 & 145 & \\
\hline 6 & 8, & & mth. & $22 \cdot 1$ & 350 & 117 & \\
\hline 7 & 9, & 11 &, & $25 \cdot 5$ & 444 & 74 & \\
\hline 8 & 11, & 10 & , & $33 \cdot 6$ & 722 & 61 & \\
\hline 9 & 11, & 11 & , & $32 \cdot 7$ & 645 & none & menstruated \\
\hline 10 & 12, & & & $44 \cdot 5$ & 802 & none & menstruated \\
\hline 11 & 12, & & & $37 \cdot 7$ & 715 & 75 & \\
\hline 12 & 12, & & mth. & 64 & 927 & 184 & \\
\hline 13 & 12, & 6 &, & $41 \cdot 2$ & 646 & 90 & \\
\hline 14 & 12, & 6 &, & 65 & 1006 & none & menstruated \\
\hline 15 & 12, & 6 & , & $51 \cdot 4$ & 816 & 77 & \\
\hline 16 & 12, & 6 & , & 51 & 831 & none & menstruated \\
\hline 17 & 12, & 7 & , & $73 \cdot 1$ & 923 & none & menstruated \\
\hline 18 & 12, & 7 & , & $37 \cdot 7$ & 817 & 77 & \\
\hline 19 & 12, & 8 & , & $73 \cdot 6$ & 1040 & none & menstruated \\
\hline 20 & 12, & 9 & , & $33 \cdot 9$ & 625 & 93 & \\
\hline 21 & 12, & 10 & , & $64 \cdot 7$ & 951 & none & menstruated \\
\hline 22 & 13, & & & $38 \cdot 2$ & 778 & none & menstruated \\
\hline 23 & 13, & & & 77 & 1252 & none & menstruated \\
\hline 24 & 13, & & mth. & $55 \cdot 9$ & 925 & none & \\
\hline 25 & 13, & $\mathbf{3}$ &, & 77 & 1231 & none & menstruated \\
\hline 26 & 13, & 5 & 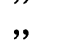 & $39 \cdot 5$ & 726 & none & menstruated \\
\hline 27 & 13, & 10 & , & $38 \cdot 2$ & 790 & 79 & \\
\hline
\end{tabular}


From the above tables it would appear that the age at which creatinuria ceases varies between twelve and fourteen years. Of the total forty-eight children twenty-nine were within these limits, nineteen being girls and ten boys. Of the nineteen girls twelve did not excrete creatine, and all of them, with one exception, had already menstruated. It will be noted that the majority of the girls at this age period who still passed creatine in the urine were nearer the age of twelve than fourteen years. Of the ten boys over twelve years only three (table 1 , no. 13, 19, 20) still passed creatine in the urine. These three boys showed normal sexual development although no pubic hair was present. One striking feature of the findings is the absence of any correlation between the age of the child and the degree of creatinuria. There is no gradual decline in the creatine excretion, as might have been expected, but a more or less sudden disappearance which, as above noted, usually takes place between twelve and fourteen years of age.

\section{Discussion.}

Various theories have been brought forward to explain the presence of creatine in the urine of the child and its absence from the urine of the adult. Powis and Raper ${ }^{1}$ believe that the explanation lies in the inability of the immature muscles during growth to utilize or metabolize creatine into creatinine. There is no doubt that muscle is essential for the conversion of creatine into creatinine, and in cases where there is much muscular degeneration, e.g., muscular dystrophy, as noted by MacCrudden and Sargent ${ }^{2}$, Gibson, Martin and Buell ${ }^{3}$ and Janney, Goodhart and Isaacson ${ }^{4}$, creatinuria may persist well into adult life, even to the age of forty-eight years. But the conception that immature muscle is incapable of causing this conversion is unlikely, since the condition of creatinuria does not, as has been noted above, gradually diminish but ceases more or less abruptly.

Rose $^{5}$ in 1911, as the result of a series of examinations of children and adolescents, noted that ' creatine is usually present in the urine until or after the age of puberty,' and he was probably the first to suggest any influence of the gonads on creatine metabolism. Rose found creatinuria in both boys and girls at the age of fifteen years, but none in any child over this age. There are, however, no girls between the ages of fifteen and twenty years, and no boys between fifteen and seventeen years in his series, so that the exact age of the disappearance of creatinuria and the relationship of this to puberty is somewhat indefinite. Moreover, it should also be pointed out that the subjects in Rose's series were on a general diet, and hence his findings leave doubt regarding the endogenous or exogenous source of the creatine present in the urine.

The decisive influence of the sex glands on the excretion of creatine is strongly supported by the findings of Remen ${ }^{6}$. This worker showed that, (1) very old people excrete a small amount of creatine even on a creatinefree diet, and that their creatine tolerance was greatly diminished; (2) a 
eunuchoid person had a constant creatinuria and a low creatine tolerance; (3) a man with a ' pituitary obesity' and hypogenitalism had a pronounced creatinuria; and (4) a man who was castrated for carcinoma of the penis reacted like the eunuchoid.

MacNeal ${ }^{7}$ also found creatinuria in eunuchoids. Buehler ${ }^{8}$ mentions a girl of eight years with precocious sexual development who reacted like an adult in that no creatine was found in the urine on a creatine-free diet. These findings-the reappearance of creatine in the urine of people whose sexual function has ceased, either through operation or old age, and its premature disappearance in children with precocious sexual developmentcertainly support the idea that the really determining factor in the utilization of creatine is the activity of the gonads. Indeed, it would seem that only on this basis can be satisfactorily explained the persistence of creatinuria during infancy and throughout childhood, and its more or less sudden disappearance at puberty.

Thanks are due to Dr. Leonard Findlay for his valuable suggestions and his kind help in the preparation of this communication.

\section{REFERENCES.}

1. Powis, F., \& Raper, H. S., Biochem. J., London, 1916, X, 363.

2. MacCrudden, F. H., \& Sargent, C. S., J. Biol. Chem., Baltimore, 1916, XXIV, 252.

3. Gibson, R. B., Martin, F. T., \& Buell, M. V., Arch. Int. Med., Chicago 1922, XXIX, 82.

4. Janney, N. W., Goodhart, S. P., \& Isaacson, V. J., ibid., 1918, XXI, 188.

5. Rose, W. C., J. Biol. Chem., Baltimore, 1911, X, 265.

6. Remen, C., Ztschr. f. d. ges. exp. Med., Berlin, 1932, LXXX, 238.

7. MacNeal, M. D., Am. J. Med. Sc., Philadelphia, 1922, CLXIV, 222.

8. Buehler, F., Ztschr. f. d. ges. exp. Med., Berlin, 1933, LXXXVI, 638. 